\title{
International Research Students' Experiences in Academic Success
}

\author{
Joanne Sin Wei Yeoh", Daniel R Terry \\ University Department of Rural Health, University of Tasmania, Launceston, 7250, Tasmania, Australia \\ *Corresponding Author: Joanne.Yeoh@utas.edu.au
}

Copyright $@ 2013$ Horizon Research Publishing All rights reserved.

\begin{abstract}
The flow of international students to study in Australia increases each year. It is a challenge for students to study abroad in a different sociocultural environment, especially for postgraduate research students, as they experience numerous difficulties in an unfamiliar and vastly different study environment. A study aimed to investigate the experiences of international research students and how this impacted upon their studies at the University of Tasmania (UTAS). This study also provides insight and guidance regarding the experiences of current and future international research students in Australia and universities globally. It also offers to educational services and relevant government agencies a greater understanding on how to support international research students more effectively. Qualitative research methods were used to gain deeper insights about the issue. Semi-structured interviews were conducted with ten participants who were selected randomly from different faculties within the university. All collected data were analysed by Nvivo version 10. Constructivist grounded theory was the basis of qualitative data analysis. The findings indicate that there are five main areas of difficulty when international research students are studying in the Australian tertiary education context. These are; language barrier, time management, research resources, educational background and cultural background. The findings of the study provide guidelines and references for current and prospective international research students in the Australian university context.
\end{abstract}

Keywords International Research Student, Academic, Language Barrier, Education Background, Cultural Background

\section{Introduction}

International students are significant stakeholders in the tertiary educational sector in Australia. In June 2013 the higher education sector was ranked first amongst all education sectors by volume of international enrolments and commencements [1]. There was a $3.3 \%$ growth in the volume of international undergraduate commencements compared with June 2012. Furthermore, international post-graduate research commencements were up by $2.5 \%$ over the same period, while other international post-graduate commencements grew by $13.7 \%$ [1]. These figures indicate that international research students are a large and indispensable population group in Australian academic discourse. The increase in enrolment numbers of international research students has greatly contributed to culture, research and the economic growth of the host country. According to Australian Education International [2] international education in 2012 contributed $\$ 15$ billion to the Australian economy in export income. Of this, higher education contributed $\$ 9.7$ billion and was the largest contributor amongst all Australian education sectors.

These statistics indicate that international students have become a significant population group which is attracting attention from governments, universities and scholars from different disciplines. The diversity of cultural and educational backgrounds which international students bring to Australia can be both a help and a hindrance to establishing their new life in a different sociocultural environment. Each international research student comes from a particular cultural background with distinct characteristics and requirements.

It is common for research students to face certain challenges within their academic candidature. Academically, it is inevitable that research students will face many pressures, such as; completing research within limited timeframes, publishing or presenting conference papers or journal articles and developing a wide range of skills that will enhance their marketability [3]. Moreover, previous literature has identified three additional academic challenges for international research students. These challenges include language barriers, learning styles and cultural background, which are discussed in detail below.

\subsection{Language Barriers}

A major concern for international students who study abroad is the language barrier [4-7]. Language plays an important role in the academic life of international students. 
Both spoken and written English challenges those international students who are from non-English speaking backgrounds (NESB), especially those with limited practice of the English language [8]. According to Rosenthal, Russell [9] who examined the health and well-being of international students from Asian countries, 24\% of international students reported that they had academic difficulties in written English, while 22\% had academic difficulties with spoken English.

Moreover, it has been shown that the lack of English language skills directly impacts upon international students in terms of their academic performance and social life [10]. International students will experience "language shock" if they lack language ability in a new environment [11]. International research students face a greater challenge in language proficiency since they are studying at a higher research degree level. If international research students have low academic English writing skills, they are likely to experience difficulties in thesis writing and in effective communication with their supervisors [12]. This directly affects student-supervisor relationships as well as students' confidence in conducting research.

\subsection{Learning Styles}

An additional challenge highlighted by international students, in their new study environments, is that the learning style is often quite different from the style that they are used to in their home countries [13]. The Asian learning style is very different from the Western learning style. It focuses more on a surface learning approach which is concerned with memorisation and reproduction as well as high achievement levels[14]. Asian education systems are more concerned with a teacher-centred approach which is the opposite of a student-centred approach [15]. The teacher-centred approach is a traditional teaching and learning process where knowledge is transmitted to students by a 'spoon-feeding' method. This can result in students being too dependent on teachers to provide all the information for them [16]. This style has a propensity to enable Asian students to academically outperform other students in Western countries in a traditional classroom setting.

However, in Western society there is often a stereotypically negative view of Asian students as passive learners. This stereotype is found in some literature and among many academic staff [17]. Nevertheless, Wong [16]demonstrates that Asian students prefer student-centred styles of learning over the spoon fed methods in their home countries. Nevertheless, there is a big impact on international research students in the process of transitioning from teacher-centred to student-centred learning [18]. They need to become more self-directed and more critical in their approach to conducting research. Thus, international research students do need time to change and adapt to an independent learning style in a new environment.
Lastly, the different cultural backgrounds of international students may also influence their learning styles in a new country. Wong's [16] study on Asian international students' learning styles highlights the premise that students' learning styles are predetermined by culture. For instance, Chinese international students are commonly categorised as passive learners [16]. They also tend to memorise facts for exam purposes due to the exam orientated culture in their home countries. Meanwhile, culture and language have a close relationship [11]. Cultural differences tend to influence language, learning and understanding. For example, in Fan's [11] study, Chinese students are shown to be confused by the use of articles within English vocabulary as there are no articles in Chinese vocabulary. Thus, it is challenging for international research students to adapt to new and unfamiliar cultures.

\section{Methodology}

\subsection{Data Collection}

The study investigated the challenges which international research students experience in their academic studies. By understanding the challenges which these students encounter, it was anticipated that the findings could lead to the development of a better environment for international students who conduct research in Australia. In the study, semi-structured interviews were conducted with ten participants who were selected randomly from different academic disciplines. The interviews were conducted face-to-face and individually. A list of ten questions were designed and used as a guide to achieve the research aims. This was achieved by asking questions that required detailed and reflective answers from each participant. All data were transcribed and analysed using the constructivist grounded theory approach [19], with the assistance of a qualitative data analysis software NVivo version 10. Throughout this process, five themes emerged at the final stage of data analysis.

\subsection{Participants}

The participants were ten international research students who were undertaking doctoral degrees at the University of Tasmania (UTAS). They were randomly selected to participate in the semi-structured interviews. Participants' demographic backgrounds were taken into consideration in order to include a diverse range of participants. Amongst the ten participants, four were from the Faculty of Education, four from the Australian Maritime College (AMC) and two were from the University Department of Rural Health (UDRH). Their home countries included China, Korea, Malaysia, Sri Lanka, Vietnam and Pakistan. The progression of each participant along their research degree trajectory ranged from less than one year to over three years. 
Participants in the interviews indicated that, as international research students, they had met some academic challenges, especially for novice researchers at the beginning of their research journey in the new sociocultural environment. Five aspects emerged:

- Language barrier

- Time management

- Research resources

- Educational background

- Cultural background

\subsection{Language Barrier}

Language barrier emerged as a significant theme within the data. Due to their limitations with English language, it was a challenge for participants to use English appropriately in their research studies. Participants faced two types of linguistic challenges in the academic field; one in academic writing and the other in verbal communication. They found that a higher level of academic English skills in both writing and verbal communication was required for research students, in order to ensure that the research experience goes smoothly.

Writing a thesis requires you to have a high level of proficiency in the English language, and in both speaking and writing. You need really good language skills to communicate with all the people that you need to interview and all the participants. (Student 2) I do have problems using scientific English words in thesis writing because I am in the science field. So, scientific English writing skill is required to guide me to write in scientific way. I need more reading to improve my English scientific terms. Research students felt stressed when they encountered thesis writing that required specific academic English writing skills.

Although academic English language was a concern amongst the international research students who were research novices, this was less of a problem for those students who had previous experience in research and thesis writing.

In thesis writing, I don't have any problems because I have done thesis writing before. I do not have problems with thesis writing. (Student 9)

In terms of verbal communication, no significant problems were discussed within the interviews. All participants indicated that they had no problems in communicating with others, no matter how long they had been in Australia. The following two examples provide some insight into why it was less of a concern.

English speaking is not a big matter for me because I have been here [Australia] for eight years. (Student 3)

Although I have only been here for five months, I do not find any problems in communicating with others in English. It is fine for me to talk in English. (Student 5)

\subsection{Time Management}

Beyond any language barrier, time management was another aspect which was felt to impact upon academic success. All participants in the study emphasised the importance of time management to achieve on-time completion of the research. The two tactics that participants mentioned using for time management were prioritising the important things and doing the 'first thing first'.

I think time management skills are quite important in $P h D$ studies. Sometimes we can't just do one thing at one time. We have to do two or three... have two or three tasks running at once. So, normally I have a plan, for example, today, I just list all the things I have to do this day from morning to afternoon. And I write down the time, such a list and put some urgent things first, and the next not urgent things behind. (Student 1)

I always set a goal for myself. I set daily, weekly and monthly goals. Although you set a goal, it is difficult to achieve or complete the goal. Normally, I will set reminders to remind myself about urgent things, in manual (calendar) and electronic (hand phone) ways. When using a calendar, I will use different colour pens to mark and represent different meanings. For example, blue means something is least important because I dislike blue. Another philosophy of mine is "Do the thing you least like." (Student 3)

However, it is not easy for a novice student to manage and plan their time.commented, It is quite a tedious task, time management. You know...I think maybe deal with the starting point of research. So once you build up with all tools, equipment, knowledge and all, at the end of the part of the research, you may realize that management is easy. At the beginning, I believe, these five months it will be hard.

On the other hand, planning something and following the plan were identified as two different things. One of the participants pointed out that it was difficult to follow exactly the plan that they had set.

The most important thing is most people plan, but it's hard to follow. So, it is very important that, you know, you have a good plan, you need to follow the plan. (Student 2).

For most of the participants, it was difficult in reality to follow their plans, particularly for part-time research students.

It's hard. I try to manage my time because I work full time. And I come out with a plan, make sure I do it so that I won't lag behind. But in reality, it is hard because you can't judge your work study, life and other thing commitment on the same scale. (Student 10)

\subsection{Research Resources}

Finding some research resources was the third concern highlighted by participants. In this high technology era, it was highlighted that it is generally easy for research students to obtain resources that related to their topic from the library, faculty and internet, in both soft and hard copies, although some comments indicated that it was difficult to get access to particular journal articles on the web.

I can easily get some resources in the university from the internet or library, but there are still some journal articles 
that I can't really access. However, I can get help from the library staff who are in charge of postgraduate studies. They will help to figure it out. (Student 1)

Moreover, the availability of research resources also depended on research topics.

My topic is quality management it is last five years we talk about quality management. Because that is part of my thesis, I cannot find rich resources here. Another part is on port, I can find it easily. I think is because of the topic on resources available. (Student 6)

\subsection{Educational and Cultural Backgrounds}

Educational and cultural backgrounds were other academic factors that affected international research students, particularly in terms of attitudes and expectations about teaching and learning styles

Ifeel it's quite different in two countries' education system. Normally, just like that, in China, we prefer passive learning and the academic environment is teacher-centred. Yes, teacher-centred. We depend on our teachers. Our teacher delivers the knowledge to us and we receive it passively. But here we have to be independent. The teachers or supervisors can't give you the answer directly. You have to explore or try to read more books or journals or something to find the answer. So I think it is a big difference. (Student 1)

The Australian educational system's rules and restrictions, in terms of ethical research and referencing, led some participants to make academic mistakes, due to their unfamiliarity with these rules.

The first thing is that in China, we don't have any ethics approval. We don't need ethics before doing research. And also... it is very hard to undertake formal interviews in China. So we have to... if you want to interview somebody or if you have to approach somebody, you just use conversation...talk to them, and to get some information from them. And for formal interview, it is quite hard to do in China. (Student 1)

The other thing I found is that in Asian countries we don't care much about referencing but here it is a big deal. Because here.... what I found different is most Asian student [undergraduate] do by heart, but here [Australia] use more independent study, like develop your own ideas, develop your mind, rather than learn things by heart. Most students have this problem, even research students; we will forget to reference our resources. When we read something, we put that in our papers or journal. We learn it and use it as our own ideas without references. And it becomes plagiarism. (Student 6)

Differences in cultural background may also result in miscommunication between international research students and English native speakers (university staff, peers, supervisors) when interacting with one another.

Because of the culture, you use the language in a different format. (Student 5)

The way you address your supervisor is different here. In Malaysia, we normally address them as Professor or something, Dr. something or you go by Mr. something, but here, the supervisors are addressed by their first name rather than their surname. (Student 8)

Lastly, it was identified that writing styles were also influenced by the cultural differences. A Chinese participant gave the following response:

In English writing, we just put in the first sentence as a topic sentence for each paragraph and then give some sentences or arguments to support the point. But in China, normally we just give the conclusion. I mean the topic sentence normally occurs in the end of the paragraph. Yes, we argue before the point, before the topic and then we just give a sentence at the end of the paragraph. (Student 1)

\section{Discussion}

Within the study, it was identified that the language barrier was a significant problem encountered by international research students who come from non-English speaking backgrounds (NESB) [7]. Inadequate English language proficiency hindered international research students' academic progress. There were two types of problems relating to language barrier identified in this study; academic writing and verbal communication. Academic writing is considered one of the biggest challenges for international research students at the beginning of their thesis writing [8]. Thesis writing requires a higher level of academic writing skills, so this has been highlighted as a tedious task for them. For science research students, they had difficulties in using scientific terms and language in thesis writing [20]. However, this was less of a concern for those research students who had previous experience in research and thesis writing. In term of verbal communication, this study found that the participants did not indicate they had many problems when communicating in English. They indicated that they communicated well with their peers, supervisors, university staff and others. It was not a significant challenge for them to understand Australian English.

Time management is essential for research students [21]. As research is an independent study, it is a requirement for each research student to have their own plan and timetable for their research in order to complete their research [22]. This is more challenging for those novice research students as they may have not fully developed time management skills required for academic life. They require more guidance and advice from supervisors in managing their time; however this may depend upon the individual. Each research student has their own personal style in planning their time, such as scheduling daily, weekly or monthly timetables, using calendars or some other way to make sure they achieve the goals they set. Hence, time needs to be individually well managed in order to achieve success in research.

Other than language barrier and time management, research students require many research resources to provide them with different ideas, information, and knowledge of their topic. The findings from this study have shown that the participants could easily access most of their resources from 
the library and the internet. Hence, this appeared to be less of a challenge for international research students than expected.

On the other hand, international research students may have difficulty in research studies when they have educational backgrounds that differ in learning style from the Australian approach. The transition from the 'spoon-fed' approach to the independent learning approach is a challenge, particularly for Asian students who have relied heavily on teachers for their learning [13]. Two common issues emerged from the data: ethical research and referencing issues. Both can lead to errors amongst international research students who are not familiar with the Australian academic policies and rules [16].

Lastly, differences in cultural backgrounds impact upon international research students. Misunderstandings and miscommunication often occurs between supervisors and international research students due to difference in cultures $[13,15]$. For instance, international research students may find it difficult to address supervisors by their first names rather than their surname with titles. In addition, writing style may also be indirectly influenced by culture [11]. Thus, international research students require time to adapt to the new culture in Australia.

\section{Recommendations and Implications}

Findings of this study were summarised in the last section. In this section, recommendations derived from the study are offered. It is hoped that these recommendations may lead to an improvement in international research students' quality of life and research studies in Australia. These recommendations can be applied across a broad range of research studies.

Recommendation 1: International research students should be well-prepared before going to study abroad.

The study has identified several challenges faced by international research students in research studies and life in Australia. The findings also indicate that international research students have difficulties both in their research studies and in their adaptation to a new environment. It is recommended that international research students make some preparations for their studies, such as reading more journal articles and books to build up their research knowledge; polishing their academic English writing and verbal communication skills; and the most important aspect is a well-prepared heart to face any challenges. Furthermore, it is wise to be fully prepared in terms of physical health and mental well-being before departing for Australia. It is vital for international research students to seek information about the country they will go to, including the weather, foods, people and culture. With full preparation in physical and psychological aspects, the success of international research students in research studies is more likely to be assured.

Recommendation 2: Supervisors should fulfil their responsibilities in cross-cultural supervision with international research students.
Supervisors are some of the most important people in leading international research students' in their research journey. It is essential for supervisors to shoulder their responsibilities in cross-cultural supervision. They should be alert and sensitive to the needs of international research students due to cultural differences. The assistance of supervisors can help to ensure that international research students achieve their targets within the limited timeframe.

\section{REFERENCES}

[1] Australian Education International. Monthly summary of international student enrolment data in Australia - YTD June 2013. Canberra: Australian Education International, 2012.

[2] Australian Education International. Export income to Australia from education services in 2012. Canberra: Australian Education International, 2012.

[3] Abiddin NZ, Ismail A, Ismail A. Effective supervisory approach in enhancing postgraduate research studies. International Journal of Humanities and Social Science. 2011;1:206-17.

[4] Roets L, editor. Challenges, opportunities and achievements of nurses' research supervision across language borders. 24th International Nursing Research Congress; 201326 July; Prague, Czech Republic: Sigma Theta Tau International.

[5] Sawir E. Language difficulties of international students in Australia: The effects of prior learning experience. International Education Journal. 2005;6:567-80.

[6] Sawir E, Marginson S, Forbes-Mewett H, Nyland C, Ramia G. International Student Security and English Language Proficiency. Journal of Studies in International Education. 2012;16:434-54.

[7] Yeh CJ, Inose M. International students' reported English fluency, social support satisfaction, and social connectedness as predictors of acculturative stress. Counselling Psychology Quarterly. 2003;16:15-28.

[8] Strauss P. 'The English is not the same': Challenges in thesis writing for second language speakers of English. Teaching in Higher Education. 2012;17:283-93.

[9] Rosenthal DA, Russell J, Thomson G. A Growing Experienc e: The Health \& Well-Being of International Students at the University of Melbourne. Mebourne: University of Melbourne, 2006 0018-1560.

[10] $\mathrm{Li} \mathrm{D}$. Coping with linguistic challenges in UK higher education: the use of strategies by Chinese research students. Language Learning Journal. 2007;35:205-19.

[11] Fan S. Language shock: A challenge to language learning. Internet Journal of Language, Culture and Society. 2010;2:42-51.

[12] McClure JW. Preparing a laboratory-based thesis: Chinese international research students' experiences of supervision. Teaching in Higher Education. 2005;10:3-16.

[13] Chung M, Ingleby R. Overcoming the cultural challenges in 
supervising Chinese research students in Australia. In: Ryan J, editor. China's Higher Education Reform and Internationalisation. London: Routledge; 2011. p. 173-92.

[14] McGowan S, Potter L. The implications of the Chinese learner for the internationalization of the curriculum: An Australian perspective. Critical Perspectives on Accounting. 2008;19:181-98.

[15] Guilfoyle A, editor. Peers, family, community, supervisors and governance: A review of key sites for supporting international postgraduate students' transitional learning experiences. Experience of Learning The 15th Annual Teaching Learning Forum; 2006 1-2 February; Perth: The University of Western Australia.

[16] Wong JK-K. Are the learning styles of Asian international students culturally or contextually based. International Education Journal. 2004;4:154-66.

[17] Chan H-T, Ryan S. Challenging Stereotypes: International
Accounting Students in Australia. Journal of Modern Accounting and Auditing. 2013;9:169-82.

[18] McClure JW. The experiences of Chinese international postgraduates studying in Singapore. Queensland: Griffith University; 2003.

[19] Charmaz K. Constructing grounded theory: a practical guide through qualitative analysis. Thousand Oaks: SAGE; 2006.

[20] Aitchison C, Catterall J, Ross P, Burgin S. 'Tough love and tears': Learning doctoral writing in the sciences. Higher Education Research \& Development. 2012;31:435-47.

[21] Abel CF. Academic success and the international student: Research and recommendations. New Directions for Higher Education. 2002:13-20.

[22] Repak N. Time management. 2011 [3 September 2013]; Available from: http://www.gradresources.org/articles/time management.shtml 